\title{
Removal of Fluorene by native and modified by linear-dendritic copolymers Laccase from Trametes versicolor
}

\author{
Mariya Brazkova, Galena Angelova, Albert Krastanov
}

\begin{abstract}
Laccases are a part of the group of multicooper-containing oxidases, which in the last decades are object of intensive study due to their broad substrate specificity. Polycyclic aromatic hydrocarbons (PAHs) are a class of hazardous organic compounds which are abundant in the environment. Fluorene is a PAH, which is very toxic to aquatic organisms, causing longterm adverse effects in the aquatic environment. In the present study laccase production of Trametes versicolor was significantly enhanced by 2-methoxyphenol as inducing compound in the cultural media. Removal of fluorene was performed with crude laccase after the process of induction. The removal efficiency at the end of the process was 0.37 at $25^{\circ} \mathrm{C}$ and 0.98 for the process at $37^{\circ} \mathrm{C}$. Laccase was isolated, purified and modified by using linear-dendritic-linear block copolymers. Spectral analysis show significantly more effective process of oxidation of fluorene by modified in comparison with the unmodified one.
\end{abstract}

Keywords - Laccase, fluorene, oxidation, Trametes versicolor

\section{Introduction}

Polycyclic aromatic hydrocarbons (PAHs) are a class of hazardous organic compounds that are widely spread in the environment. The main sources of PAHs are the incomplete combustion of organic matter, internal combustion engines and different industrial processes [1]. PAHs can contain two or more fused benzene rings. In this regard they can be divided in two groups: PAHs with low molecular weight and PAHs with high molecular weight. The compounds from the first group have in their molecule up to three fused rings, and PAHs from the second group have four or more aromatic rings in their structure. PAHs are often found in groups in the environment. They are persistent, which makes them a concern for the environmental pollution as well as for animal and human health. Fluorene (fig 1) is formed of three fused aromatic rings. It forms white crystals with specific odor, similar to the one of naphthalene.

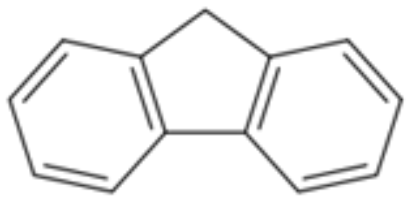

Fig.1 Structure of fluorene

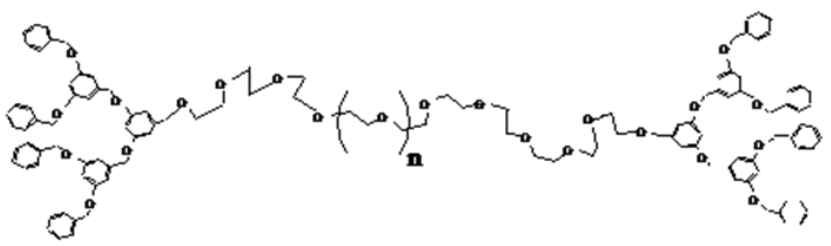

Fig.2 Structure of dendritic-linear-dendritic copolymer

Fluorene is used as a chemical intermediate in many processes and in the formation of polyradicals for resins. Like most PAHs fluorine is used for dyes and plastic manufacturing and for the production of pesticides.

During the last decade laccases ( $\rho$-diphenol:dioxygen oxidoreductases, EC 1.10.3.2) are object of intensive research regarding to their capability to oxidize persistent environmental pollutants. Laccase production is defined mainly of the cultivation conditions and from the cultural media composition. Trametes versicolor produces its lignin degrading complex during the secondary metabolism and it is usually initiated by increased nitrogen concentration in the media or limited carbon source. Normally laccase is produced in small amounts from the white-rot fungi but the synthesis could be enhanced by the addition of inducers [2, 3]. Those inducers are mainly phenolic and aromatic or lignin related compounds. The addition of such substances leads to increasing the fields of application of Trametes versicolor's laccase. Those enzymes have broad substrate specificity but their oxidation potential limits with only water soluble substrates. Linear-dendritic block copolymers have the ability to selectively adhere to various surfaces and they are have the quality to bind substantial amount of hydrophobic substrates in aqueous medium [4, 5]. The enzymatic nanoreactors used in the present study were formed by noncovalent envelopment of a glycoprotein by amphiphilic dendritic-linear-dendritic copolymers (fig.2).

The aim of the present work is to study the efficiency of the fluorene removal by crude laccase from Trametes versicolor, induced by 2-methoxyphenol in comparison with modified by linear-dendritic copolymers enzyme.

\section{Materials and Methods}

\section{A. Fungal strain}

The fungal strain Trametes versicolor 1 was provided by the Department of Biotechnology, University of Food Technologies - Plovdiv, Bulgaria. The strains is maintained on $1.5 \%$ Czapek-Dox Agar and stored at $4^{\circ} \mathrm{C}$. 


\section{B. Cultivation conditions. Enzyme assay.}

Czapek-Dox liquid media, containing sucrose - 30g/L; yeast extract $-5 \mathrm{~g} / \mathrm{L} ; \mathrm{NaNO}_{3}-2 \mathrm{~g} / \mathrm{L} ; \mathrm{K}_{2} \mathrm{HPO}_{4}-1 \mathrm{~g} / \mathrm{L}$; $\mathrm{MgSO}_{4}-0.5 \mathrm{~g} / \mathrm{L} ; \mathrm{KCl}-0.5 \mathrm{~g} / \mathrm{L}$ and $\mathrm{FeSO}_{4}-0.01 \mathrm{~g} / \mathrm{L}$ was used for cultivation of Trametes versicolor 1 . The $\mathrm{pH}$ prior sterilization was adjusted to 6.5 using $2 \%$ sulfuric acid.

Different concentrations in the range of $0-20 \mathrm{mM}$ of $2-$ methoxyphenol were used in order of enhancing the biosynthesis of enzymes. The inoculation was made with $5 \%$ spores suspension of 7 days old culture from Trametes versicolor 1 . The fermentation process was performed for 7 days at $28^{\circ} \mathrm{C}$ on a rotary shaker at $220 \mathrm{rpm}$.

After the end of the cultivation process the dry weight of the biomass, the protein concentration, the activity of the manganese-dependent peroxidase and laccase were determined. The dry weight was determined using RADWAG MA 50/1.R moisture analyzer where the biomass was dried at $105^{\circ} \mathrm{C}$ until constant weight.

Laccase activity was determined using syringaldazyne as substrate. The reaction mixture contained cultural broth, $50 \mathrm{mM}$ potassium phosphate buffer $(\mathrm{pH} 4.5)$ and $0.216 \mathrm{mM}$ substrate solution. The change of absorption values at 530 $\mathrm{nm}$ was monitored at $37^{\circ} \mathrm{C}$ for 5 minutes. One unit of enzyme activity corresponds to 0.001 change in OD at the reaction conditions and it is expressed in units per $\mathrm{mL}$. The activity of the manganese-dependent peroxidase (MnP) was determined by measuring the oxidation of $\mathrm{Mn}$ (II) to $\mathrm{Mn}$ (III) at $270 \mathrm{~nm}$, according to the method of Warshii et al. [6]. The reaction mixture contained $1.0 \mathrm{mM} \mathrm{MnSO}_{4}$ in $50 \mathrm{mM}$ sodium malonate buffer $(\mathrm{pH} 4.5)$ and the reaction was started by the addition of $0.5 \mathrm{mM} \mathrm{H}_{2} \mathrm{O}_{2}$ solution. One unit of enzyme activity was defined as the enzyme quantity required to oxidize $1 \mu \mathrm{mol}$ substrate for 1 minute at the reaction conditions. The total protein concentration was monitored using the "Bradford" method [7].

\section{Removal of fluorene. Extraction. HPLC analysis.}

After the end of the fermentation the biomass was separated from the media by centrifugation at $6000 \mathrm{rpm}$ for 5 minutes. The cultural broth was used as medium for removal of fluorene. In $10 \mathrm{~mL}$ cultural broth, fluorene with concentration of $200 \mathrm{mg} / \mathrm{L}$ was added in dry form. The process was maintained at two different temperatures $-25^{\circ} \mathrm{C}$ and $37^{\circ} \mathrm{C}$ with duration of 15 days. Concentration of residual fluorene and enzyme activities were analyzed at $1^{\text {st }}, 2^{\text {nd }}, 3^{\text {rd }}$, $5^{\text {th }}, 10^{\text {th }}, 12^{\text {th }}$ and $15^{\text {th }}$ day.

Fluorene was extracted from the cultural broth using toluene as extracting agent. After triplicate extraction the crude extracts of organic phase were dried by adding of $\mathrm{NaSO}_{4}$. Then the samples were evaporated under vacuum, resuspended in acetonitrile and filtered through $0.45 \mu \mathrm{m}$ membrane filter. Aliquot of $20 \mu \mathrm{L}$ was taken for chromatographic analysis. The HPLC determination was performed at Agilent 1200 Infinity Series equipped with UV-detector. The separation column was Zorbax Eclipse PAH with $5 \mu \mathrm{m}$ particle size and $4.6 \mathrm{~nm}$ inner diameter and $150 \mathrm{~mm}$ length. Acetonitrile (HPLC grade, Merck) was used as mobile phase at flow rate of $1 \mathrm{~mL} / \mathrm{min}$. The detection was made at $220 \mathrm{~nm}$. Each sample was injected at least three times and the mean was calculated.

The removal of fluorene $(\mathrm{R}, \%)$ and the removal efficiency $(\eta)$ were calculated using the formulas below:

$$
\begin{gathered}
R=\left[\frac{(C o-C)}{C_{o}}\right] * 100 \% \\
\eta=1-\left(\frac{C}{C_{0}}\right)
\end{gathered}
$$

$\mathrm{C}_{\mathrm{o}}$ - initial concentration of fluorene, $\mathrm{mg} / \mathrm{L}$

$\mathrm{C}$ - concentration of fluorene on the state, $\mathrm{mg} / \mathrm{L}$

\section{Isolation and purification of laccase}

After the end of the fermentation process the cultural broth, containing the enzyme was filtered using glass fiber filters, brand G-6, followed by ultrafiltration with was performed using Milipore Prep/Scale-TFF ultrafiltration unit and a $400 \mathrm{~mL}$ Amicon stirred pressure cell, equipped a polyethersulfonate ultrafiltration membrane with $30000 \mathrm{Da}$ molecular cutoff. Size exclusion chromatography was the final step of the purification process, were Sephacryl 200HR was used. The blue colored fractions were collected, combined and concentrated again for gain of relatively homogeneous enzyme.

\section{E. Preparation of Laccase complex with the block copolymers}

The dendritic-linear-dendritic copolymers [G-2] PEG5k - [G-2], [G-3] - PEG11k - [G-3] and [G-4] PEG11k - [G-4] were synthesized from reactive poly(benzyl ether) monodendrons of second, third and fourth generation by coupling with preformed poly(ethylene glycol)s of molecular weight of $5000 \mathrm{Da}$ or $10800 \mathrm{Da}$ [8]. They were generously provided by the Department of Chemistry of SUNY College of Environmental Science \& Forestry, Syracuse, NY, USA.

The solution of the purified enzyme $(1 \mathrm{~mL}, 2 \mathrm{mg} / \mathrm{mL}$ protein concentration) was combined with $0.007 \mathrm{~g}$ of dendritic-linear-dendritic copolymers in dry form. Deionized water was added to make a final volume of $10 \mathrm{~mL}$ after which the mixture was stirred on 3D rotary shaker at $4^{\circ} \mathrm{C}$ for $12 \mathrm{~h}$ follow by stirring at room temperature for $8 \mathrm{~h}$.

Fluorene was added in $200 \mathrm{mg} / \mathrm{L}$ concentration in $10 \mathrm{~mL}$ of the mixture containing the modified in copolymers enzyme. Experimental tubes were then placed on rotary shaker at $37^{\circ} \mathrm{C}$.

\section{F. Spectral analysis}

The spectral analysis were performed on SpectroStar Nano UV-vis spectrophotometer (BMG Labtech) at room temperature with a scan speed of $1200 \mathrm{~nm} / \mathrm{min}$ over a range of $220-950 \mathrm{~nm}$, with $2 \mathrm{~nm}$ resolution. A COSTAR 96-well UV plate was used and $200 \mu \mathrm{l}$ of the reaction mixture were taken for scanning. 


\section{Results and discussion}

\section{A. Induction of enzyme synthesis}

The inducing substance, 2-methoxyphenol, was used in increasing concentration from $1 \mathrm{mM}$ to $20 \mathrm{mM}$. The dry weight of the biomass was determined after cultivation at each concentration. The results obtained showed that there was significant decrease in biomass concentration where the 2-methoxyphenol concentration was over $4 \mathrm{mM}$ (fig.3). Nevertheless there is no correlative connection between the biomass and the laccase gain. The analysis of the laccase activity after each induction process showed that $6 \mathrm{mM}$ concentration of the inducing compound is optimal for producing enzyme with maximum activity (fig.4). The activity of $\mathrm{MnP}$ is also optimal at $6 \mathrm{mM}$ concentration of 2methoxyphenol. The enzyme is stable at lower concentrations of the substance (fig.5), but concentrations over $8 \mathrm{mM}$ lead to sudden decrease in the activity of the $\mathrm{MnP}$, as well as in the laccase activity. Compared with the results of previous research, [2], 2-methoxyphenol is the best inducer of the enzymes synthesis. The increase of the laccase activity was nearly 10 folds from $668 \mathrm{U} / \mathrm{mL}$ in the cultural broth without inducing component to $6468 \mathrm{U} / \mathrm{mL}$ in the cultural broth containing $6 \mathrm{mM} 2$-methoxyphenol. The activity of $\mathrm{MnP}$ was increased with $32.4 \%$ from $52.5 \mathrm{U} / \mathrm{mL}$ to $69.5 \mathrm{U} / \mathrm{mL}$.

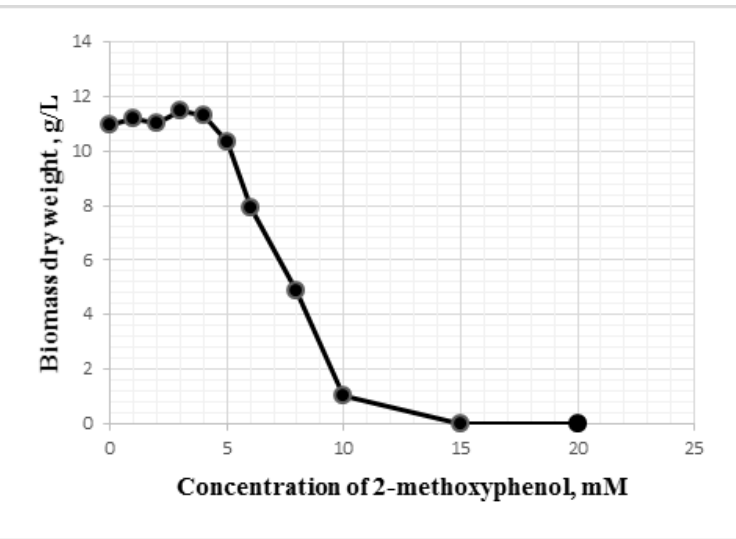

Fig.3 Effect of 2-methoxyphenol on biomass gain

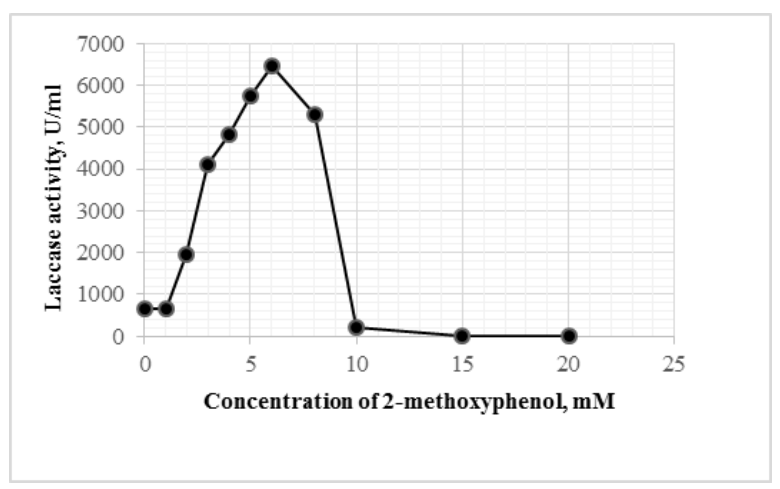

Fig.4 Effect of 2-methoxyphenol on laccase activity

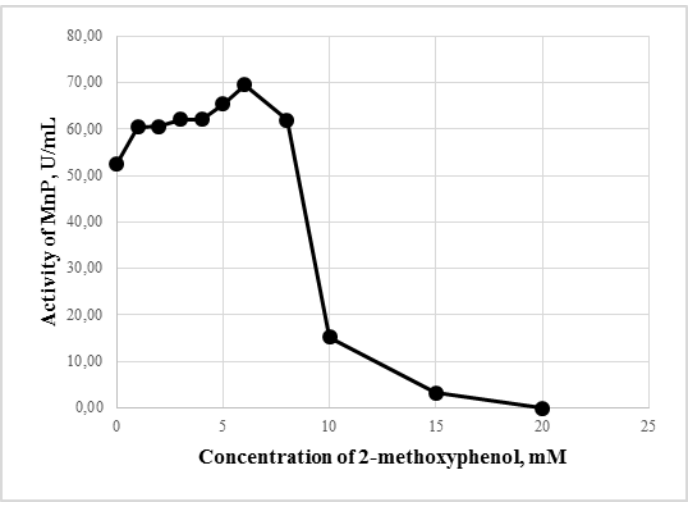

Fig.5 Effect on 2-methoxyphenol on MnP activity

Therefor further in the experiments $6 \mathrm{mM} \quad 2$ methoxyphenol was used as inducer.

\section{B. Fluorene removal}

Trametes versicolor has the ability to degrade persistent environmental pollutants using its ligninolytic enzymatic system. Laccase is known to be able to oxidize various phenolic compounds, sometimes with the help of mediators [9]. The medium in which the experiment took place contained crude laccase and MnP (cultural broth, centrifuged at $6000 \mathrm{rpm}$ for separation of the biomass), and fluorene, added in dry form, in concentration $200 \mathrm{mg} / \mathrm{L}$. Fig. 6 shows the removal of fluorene $(\mathrm{R})$ during the experimental procedure at $25^{\circ} \mathrm{C}$ and $37^{\circ} \mathrm{C}$. On the first day of the experiment at $25^{\circ} \mathrm{C}$, a residual fluorene concentration of 145 $\mathrm{mg} / \mathrm{L}$ was detected. The concentration of residual fluorene in the samples placed at $37^{\circ} \mathrm{C}$ was $125 \mathrm{mg} / \mathrm{L}$.

Until the $15^{\text {th }}$ day there was no significant change in the residual fluorene detected at $25^{\circ} \mathrm{C}$. The highest removal rate was on the last day and it equals to $37 \%$ or $75 \mathrm{mg} / \mathrm{L}$ fluorene removed. The data from the process carried out at $37^{\circ} \mathrm{C}$ was impressing. After $24 \mathrm{~h}$ at the reaction conditions $75 \mathrm{mg} / \mathrm{L}$ were removed and the oxidation continued to the $15^{\text {th }}$ day where the removal rate was $98 \%$. The removal efficiency at the end of the process was 0.37 for the process at $25^{\circ} \mathrm{C}$ and 0.98 for the process at $37^{\circ} \mathrm{C}$. In the control samples fluorene concentration remain constant during the whole process which gave us the clue that the decrease in the concentration of fluorene is only due to the oxidative activity of the enzymes.

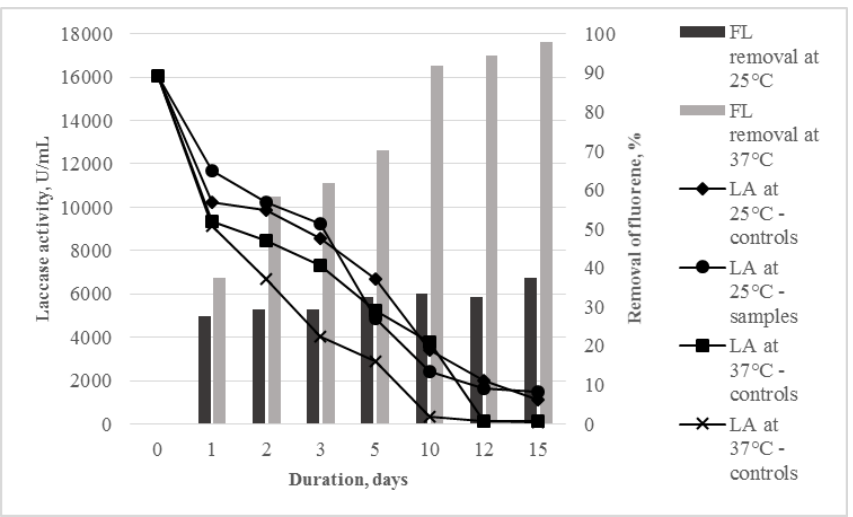

Fig.6 Fluorene removal by crude laccase and MnP, and laccase activity at different temperatures during the experiment 
Laccase activity was also monitored during the process. The enzyme was active until the end of the process but lost $50 \%$ of its initial activity by the $5^{\text {th }}$ day at $37^{\circ} \mathrm{C}$ and by the $10^{\text {th }}$ day at $25^{\circ} \mathrm{C}$. Despite the decrease of the laccase activity, the fluorene removal continues. This is due to the fact that the oxidation processes that take place in fluorene removal have chain-like characteristics. In this process the oxidized molecules continue to oxidase more fluorene molecules leading to increasing of the removal efficiency. The high removal rate is also a result of the lignin-degrading enzymatic complex activity, combined with the optimal temperature for the laccase action. The removal process took place in aquatic media. To our knowledge there is no research based on the fluorene removal with the usage of crude enzyme solution from Trametes versicolor. Akdogan et al. [10] used mediums containing different saline concentrations and Trametes versicolor strain for fluorene removal. The highest biodegradation rate was $54 \%$ and it was detected when an initial concentration of $5 \mathrm{mg} / \mathrm{L}$ fluorene was used. In the present study $98 \%$ removal of fluorene, with initial concentration of $200 \mathrm{mg} / \mathrm{L}$, from the reaction media was achieved for the period of 10 to 15 days. This successful results is due most likely to the combination of the lignin-degrading complex (laccase, $\mathrm{MnP}$ ) activity and the optimal temperature.

\section{Monitoring of fluorene transformation by modified laccase}

The goal of this study is to illustrate the outlined approach with the enzyme laccase and amphiphilic block copolymers containing linear poly(ethylene glycol), PEG and dendritic poly(benzyl ether)s. To our knowledge, the use of laccase-normal micelle complexes for the oxidation of fluorene in aqueous medium has not been reported. In this study we explore the catalytic activity of laccase from Trametes versicolor 1 embedded into normal micelles formed by a dendritic-linear-dendritic copolymers (fig.2), The experiment regarding laccase modification were performed with single laccase solution and the results observed could be due solely to the influence of the reaction conditions. The reaction mixture is formed by adding the components in specific order as follows: (1) enzyme in buffer solution, (2) copolymer in dry form and (3) fluorene in dry form. If different order of addition is applied the adhesion of the copolymers to the enzyme will be prevented and this will result in forming either empty copolymer micelles or substrate loaded ones.

An initial quantity of $200 \mathrm{mg} / \mathrm{L}$ of fluorene was introduced into the samples. Spectral analysis took place at every hour during the first five hours, and every 24 hours after that until the $48^{\text {th }}$ hour of the experiment. The biotransformation of fluorene is followed by UV-Vis spectroscopy (fig.7). Parallel measurements without the linear-dendritic copolymer are also made under identical reaction conditions. It is seen that the spectra changes in the different reaction mixtures over time. The spectroscopic analyses reveal that the mixtures containing laccase modified with [G2]-PEG5k-[G2] show a broad absorbance in the region $220-420 \mathrm{~nm}$ increasing with time (fig. $7 \mathrm{~b}$ ). It is clear that the most significant spectral changes occur in the mixture, containing [G-2] - PEG5k - [G-2] polymer.
Those changes are almost instantly starting with the mixing of the components. In comparison with the other graphs here dynamic and rapid changes in the spectra were observed for the first 5 hours of the experiment, but the biggest difference between the spectral curves was observed between the $5^{\text {th }}$ and $24^{\text {th }}$ hour. At fig. 5 c) where [G-3] - PEG11k - [G-3] polymer was used spectral changes also occur, but in not so dynamic way as in the previous graph. The changes during the first five hours were not so dynamic, but are clearly visible. Again the biggest change in the spectral curves was observed at the $24^{\text {th }}$ and the $48^{\text {th }} \mathrm{h}$. When the [G-4] PEG11k - [G-4] polymer was used the only significant change appears at the spectral curve of the $48^{\text {th }}$ h. Both figures c) and d) are similar to a) where the enzyme solution wasn't modified with polymer. This means that the modification with [G-2] - PEG5k - [G-2] is the most successful one.

a)

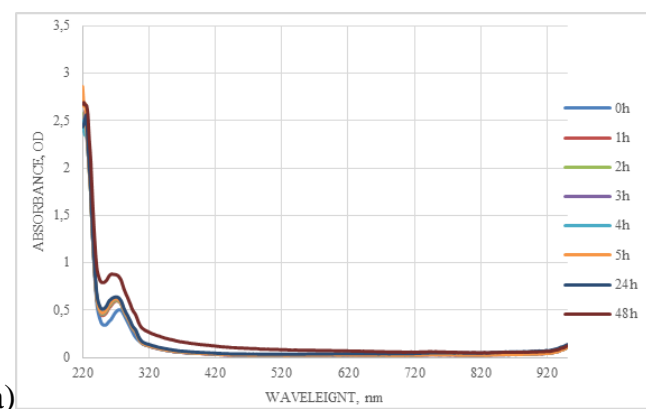

b)
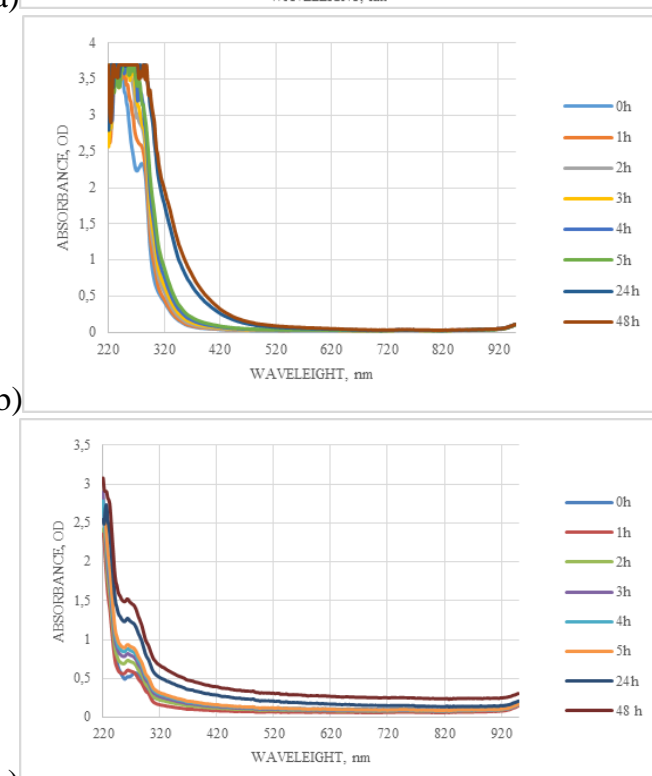

c)

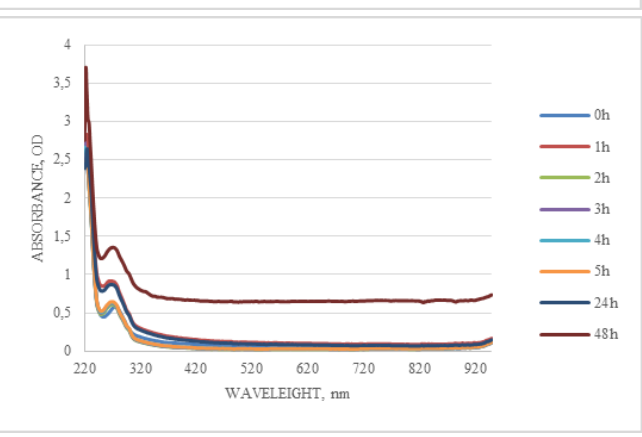

Fig.7 UV-Vis spectra of aqueous reaction mixture containing fluorene and a) native enzyme solution; b) enzyme encapsulated with [G-2] - PEG5k [G-2] polymer; c) enzyme encapsulated with [G-3] - PEG1 1k - [G-3] polymer and d) enzyme encapsulated with [G-4] - PEG11k - [G-4] polymer 
The observed changes in the spectral curves are result of oxidation processes that took place in the reaction mixture. During the oxidation of fluorene probably new compounds were formed. The control samples contained native enzyme, modified enzyme or fluorene with polymer and showed no changes in the spectral curves during the experiment. The most significant spectral changes were observed at $400 \mathrm{~nm}$. Spectral data showed (fig.8) there is most likely no difference in the structure of the compounds, formed due to the oxidation processes when native enzyme solution and [G-4] - PEG11k - [G-4] polymers were used. When [G-3]PEG11k - [G-3] and [G-2] - PEG5k - [G-2] polymers were tested there is significant change in the absorbance values. Those differences are probably due to the intense oxidation processes leading to formation of different intermediate products with different molar attenuation coefficient.

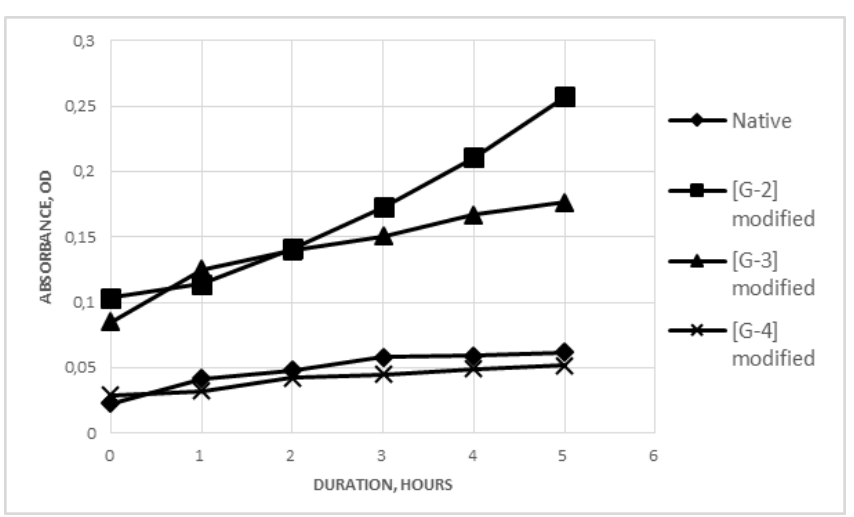

Fig 8. Changes in the absorbance at $400 \mathrm{~nm}$ of different enzyme preparations

The process of envelopment of the laccase with lineardendritic copolymers is a way for the enzyme to be involved of oxidation processes of insoluble persistent phenolic and aromatic environmental pollutants in aquatic media. With the modification of the crude laccase solution the time needed for fluorene removal/biotransformation was reduced from 15 days to $48 \mathrm{~h}$. This approach could be successfully used for the needs of green chemistry and for the removal of other PAHs and insoluble hazardous pollutants.

Further analysis are necessary for determination the exact pathway of fluorene oxidation and also determination the removal rate of the compound when modified enzymes are used.

\section{Conclusions}

In this study a successful method for oxidation of fluorene using cultural broth with induced laccase activity was presented. To our knowledge this is the first research regarding fluorene removal/biotransformation in aquatic media without the presence of mediators. The removal rate of fluorene from the reaction mixture after 15 days at $37^{\circ} \mathrm{C}$ was $98 \%$. The data of the current investigation show that laccase surface-modified with the amphiphilic copolymer [G2]-PEG5k-[G2] is capable of oxidative transformation of highly hydrophobic PAHs (fluorene) without the presence of mediators. When the [G-2] - PEG5k - [G-2] lineardendritic linear copolymer was used for modification of the purified enzyme, the changes in the spectral curves were most significant. Those changes most probably are due to oxidation processes in the mixture containing fluorene and modified enzyme. The time needed for fluorene removal/biotransformation in this case was reduced to $48 \mathrm{~h}$.

\section{Acknowledgment}

This study would not be possible without the generous contribution of Prof. Ivan Gitsov from the Department of Chemistry at SUNY College of Environmental Science \& Forestry, Syracuse, NY, USA.

\section{References}

[1] B. Maliszewska-Kordybach, Sources, Concentrations, Fate and Effects of Polycyclic Aromatic Hydrocarbons (PAHs) in the environment. Part A: PAHs in the Air, Polish Journal of Environmental Studies, Vol.8, No.3, 1999, 131-136

[2] Mariya Brazkova, Albert Krastanov, Effect of various inducers on laccase production by Trametes versicolor 1 , Scientific works of UFT, v. LX, p. 1030-1033, 2013

[3] A.M.R. Barreto Xavier, A.P.M. Tavares, R. Ferrera, F. Amado, Trametes versicolor growts and laccase induction with by-products of pulp and paper industry, Electronical Journal of Biotechnology, Vol.10, No.3, 2007, 444-451

[4] A. Krastanov, R. Koleva, I. Stoilova and Z. Alexieva, Decolorization of industrial dyes by immobilized mycelia of Trametes versicolor. Biotechnol \& Biotechnol. Eq., 2013, 27(6), p. 4263-4268

[5] C.A. Reddy, The potential of white-rot fungi in treatment of pollutants. Current opinion in Biotechnology. 1995, 6, p. 320-328

[6] H. Wariishi, H.B. Dunford, I.D. MacDonald, M.H. Gold, Manganese Peroxidase from the lignin-degrading Basidiomycette Phanerochaete chrysosporium, The journal of Biological Chemistry, Vol.264, No.6, 1989, 3335-3340

[7] Marion M. Bradford, A Rapid and Sensitive Method for the Quantitation of Microgram Quantities of protein Utiliting the principle of Protein Dye-Binding, Analytical Biochemistry, 72, 1976, 248-254

[8] I. Gitsov, K.L. Wooley, J.M.J. Frèchet, Novel polyether copolymers consisting of linear and dendritic blocks. Angewandte Chemie International Edition in English. 1992, 31(9), p. 1200-1202

[9] I. Gitsov, A. Simonyan, L. Wang, A. Krastanov, S. Tanenbaum, D. Kiemle, Polymer-Assisted Biocatalysis: Unprecedented Enzymatic Oxidation of Fullerene in Aqueous Medium, Journal of Polymer Science Part A: Polymer Chemistry, 2012, 50: 119-126

[10] H.A. Akdogan, N. Pazarlioglu, Fluorene removal from Synthetically Concocted Marine Water by Trametes versicolor, Asian Journal of Chemistry, Vol.23, No.6, 2011, 2548-2552

About Author (s):

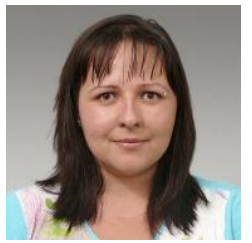

Mariya Brazkova, Dipl. Eng., MSc

$\mathrm{PhD}$ student at Department of Biotechnology, University of Food Technologies - Plovdiv, Bulgaria

Research interests: Biodegradation of persistant environmental polutants

Albert Krastanov, Professor, Dipl.Eng., $\mathrm{PhD}, \mathrm{DSc}$

Head of Depratrment of Biotechnology University of Food Technologies - Plovdiv, Bulgaria

Galena Angelova, Dipl. Eng, $\mathrm{PhD}$

Head Assistant-Professor at Department of Biotechnology, University of Food

Technologies - Plovdiv, Bulgaria 